Sharif University of Technology
Scientia Iranica
SCIENTIA

\title{
Demand response as a complement for wind energy from the viewpoint of system well-being
}

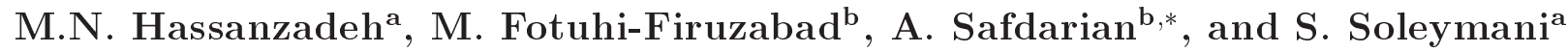 \\ a. Department of Electrical and Computer Engineering, Islamic Azad University, Science and Research Branch, Tehran, P.O. Box \\ 14777893855, Iran. \\ b. Center of Excellence in Power System Control and Management, Department of Electrical Engineering, Sharif University of \\ Technology, Tehran, P.O. Box 11155-8639, Iran.
}

Received 7 August 2016; received in revised form 22 July 2017; accepted 23 June 2018

\section{KEYWORDS \\ Demand side management; Dynamic pricing; Elasticity coefficient; Wind energy sources; Well-being analysis.}

\begin{abstract}
The risk imposed by the stochastic nature of wind energy sources has always been a major barrier despite their proliferation in power systems. To further penetrate these sources, this paper draws upon dynamic prices, which realize demand response potentials along with decimating the risk involved. To do so, a model is first established to study the impact of activating demand response on the risk index in a system with a high penetration of wind resources. Then, the model is used to estimate the extra wind capacity that can be hosted by the system such that the risk remains within the acceptable range. The well-being indices are calculated via sequential Monte Carlo simulation approach and fuzzy theory. The demand response with dynamic prices is modeled by self and cross elasticity coefficients of different load sectors. The performance and applicability of the proposed model are verified through simulations on the IEEE Reliability Test System (IEEE-RTS).
\end{abstract}

(C) 2020 Sharif University of Technology. All rights reserved.

\section{Introduction}

Due to its economic and environmental benefits, wind energy has mainly been envisioned to play an indispensable role in future energy systems. The stochastic nature of this energy source, however, has negative impacts on the safe operation of power systems [1]. This drawback is even more highlighted in power systems with higher wind penetrations. In the literature, several solutions have been proposed to mitigate concerns about the risk of uncertain sustainable energy

*. Corresponding author. Tel.: +982166165901

E-mail addresses: nasehhasanzadeh1@gmail.com (M.N.

Hassanzadeh); fotuhi@sharif.edu (M. Fotuhi-Firuzabad);

safdarian@sharif.edu (A. Safdarian);

s.soleymani@srbiau.ac.ir (S. Soleymani)

doi: $10.24200 /$ sci. 2018.20605 sources like wind. In [2], energy storage units were proposed to tackle deviations in the output power of wind sources. It was demonstrated that the optimal location and capacity of distributed generation in a grid could be determined by quantifying the hosting capacity of different nodes of the grid. As found in that study, the marginal benefit of the battery decreases by increasing storage size. In [3], hybrid renewable energy resources were applied to increase the availability of output power of these sources. These methods, however, are more beneficial in areas where at least two different renewable energy sources are profitable and applicable. In [4-8], demand response was proposed as a complement for uncertain energy sources like wind. In [4], by using a case study based on the ERCOT (Electric Reliability Council of Texas) power system, system operating cost was compared when imperfect forecasts and perfect foresight of wind 
were available. They demonstrated that wind uncertainty could impose substantive costs on the system and that demand response could eliminate more than $75 \%$ of these costs if consumers responded to system conditions immediately. The research reported in [5] simulated and compared system operation with high wind penetration levels with and without applying real-time prices. It was shown that activating demand response with Real-Time Pricing (RTP) could increase the percentage of load that might be served by wind generation. In [6], RTP and Demand-Side Management (DSM) were proposed to increase the penetration of wind energy. It was shown that offering dynamic tariffs to customers could increase the benefit of sustainable energies on both supply and demand sides. It was also demonstrated that wind penetration could be increased by $40 \%$ if RTP and DSM were applied together [7]. According to this study, an increment in the production of wind energy sources can be translated to a reduction in energy price, thereby motivating consumers to consume more. On the other hand, higher energy prices due to low wind generation encourage consumers to consume less. This implies that the availability of wind energy and demand is more correlated when demand response is activated via dynamic prices. According to the study, the idea of applying dynamic prices to correlate wind energy with system demand was proposed. However, it lacked a comprehensive study on risk indices. It is also required to quantitatively assess the impacts of using demand response on the maximum allowed penetration of wind. To this end, this paper aims to establish a model to quantify well-being indices in systems with high penetrations of wind energy when demand response is activated. The model is then used to estimate the extra wind capacity that can be hosted by the system if demand response potentials are realized through dynamic prices. This study is required to quantify the contribution of demand response concerning the increased penetration of wind in future power systems. The demand flexibility behavior in response to dynamic prices is captured via price elasticity coefficients $[8,9]$. The model investigates various sectors of load with various elasticity levels and energy use profiles. The risk assessment is subjected to the system well-being, where (sequential) Monte Carlo simulation and fuzzy theory are practiced. The effectuality of the offered model is unveiled by applying it to the IEEE-RTS.

\section{Preliminart bases}

In this section, the significant-on-paper concepts used in the evolved model are briefly described. Here, quick descriptions of the investigated model for Wind Energy Conversion Systems (WECS) and well-being analysis are given .

\subsection{Wind Energy Conversion System ( WECS)}

An essential prerequisite for incorporating WECS in generation system well-being analysis is to counterfeit the hourly wind speed. There are different approaches in the literature to modeling wind speed [10]. ARMA, as a very popular approach, uses the correlation between wind speed at a specific hour and wind speed within immediate previous hours. The general definition of the $\operatorname{ARMA}(n, m)$ model is presented here [11]:

$$
y_{t}=\sum_{i=1}^{n} \Phi_{i} \times y_{t-i}+\alpha_{t}-\sum_{j=1}^{m} \Theta_{j} \times \alpha_{t-j} .
$$

The simulated wind speed at time $t$, i.e., $W K_{t}$, is calculated as follows [11]:

$$
W K_{t}=\mu_{t}+\sigma_{t} \times y_{t} .
$$

After determining the hourly wind speed, the next step is to determine the power output of a Wind Turbine Generator (WTG) as a function of wind speed. This function is represented by the distinctive parameters of a WTG. Here, Eq. (3) is used to retrieve the hourly power production of a WTG from the simulated Hourly Wind Speed (HWS) [12].

$P\left(W K_{t}\right)=\left\{\begin{array}{cc}0 & W K_{t} \leq V_{c i} \\ a+b \times W S_{t}+c \times W S_{t}^{2} & V_{c i} \leq W K_{t} \leq V_{r} \\ 0 & V_{c o} \leq W K_{t}\end{array}\right\}$

\subsection{Well-being analysis}

Traditionally, power system operating states have been represented by a five-state model including normal, marginal, emergency, extreme emergency, and restorative states. These five operating states, however, do not appropriately reflect the actual system risk level [13]. To address this issue, the five-state model is then transformed into a wellbeing analysis framework [14]. This framework is considered to evaluate system wellbeing in serving load via a set of probabilistic criteria, as displayed in Figure 1. The system is supposed to be in the healthy state if system load is served and enough reserve is available to meet analytic norms like

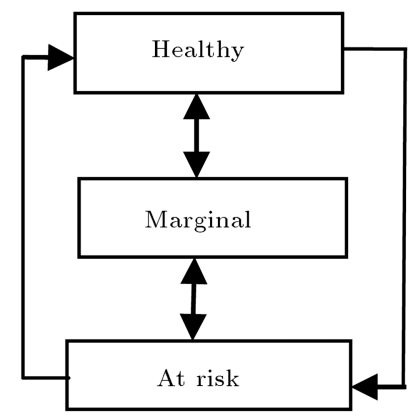

Figure 1. System well-being model. 
the loss of the largest available unit. The system is in its marginal state if no problem arises in serving the load, while the reserve is not adequate to withstand the analytical criteria. This means that, in the marginal state, the available reserve is not sufficient to bear when the largest operating unit is lost. In the at-risk state, system load overrides the available generation capacity; therefore, load shedding is inevitable. The three abovementioned states serve as the system well-being indices.

Among a variety of simulation methods and analytical criteria used for calculating the system wellbeing criteria, the sequential Monte Carlo simulation method is used in this paper. The available capacity of the generating system is obtained through random sampling from the down and up modes of the generating units $[15,16]$. The procedure used for calculating the system well-being criteria is displayed schematically in Figure 2 [17]. In the figure, the red diagram represents the overall available generation capacity, the blue diagram is the available capacity minus the largest available unit at that hour, and the green diagram is load value. $t(H)$ represents the time when generation minus the largest available unit is greater than load value, and the system is in a healthy state. $t(M)$ denotes the time when generation capacity minus the largest available unit is less than the load and, yet, the overall generation is greater than the load, and the system is in the marginal state. Finally, the at-risk state emerges when the generation is less than the load.

The probability of the system in each state is finally calculated by summing up the associated duration times divided by the duration of the simulation period.

\section{Developed methodology}

This section develops a step-by-step procedure to include demand response and wind penetration in assessing the generation system well-being. The flowchart of the approach can be seen in Figure 3, which is described in the following:

Step 1: All system data including load of different sections, generator information, and information of wind turbines and wind speed specifications are determined;

Step 2: In this step, the availability and unavailability of the traditional units are determined by the Monte Carlo method. Wind speed is also calculated by applying sequential Monte Carlo simulation and time-series ARMA model. In reality, the availability of generating units and wind speeds of the hour is determined by which access capacity can be obtained per hour over time;

Step 3: The calculated wind speed is combined with the WTG model, given in Eq. (3), to estimate the power output of wind turbines. The output of this step is the hourly generation of wind turbines within the simulation period;

Step 4: In this step, the hourly available conventional generation capacity obtained in Step 2 and hourly production of wind turbines achieved in Step 3 are combined, and the hour-by-hour total generation capacity is calculated;

Step 5: The total consumption of loads in different sectors including large user, governmental, etc. is shown, and the total hourly load of the system is calculated in this step;

Step 6: This step is to calculate hourly electricity prices based on cost functions associated with generating units at the associated hour and the respective system load. It is worth mentioning that the generation cost of wind turbines is considered negligible. The electricity price at a specific hour is considered equal to the marginal production cost of the last collaborative unit at the same hour.

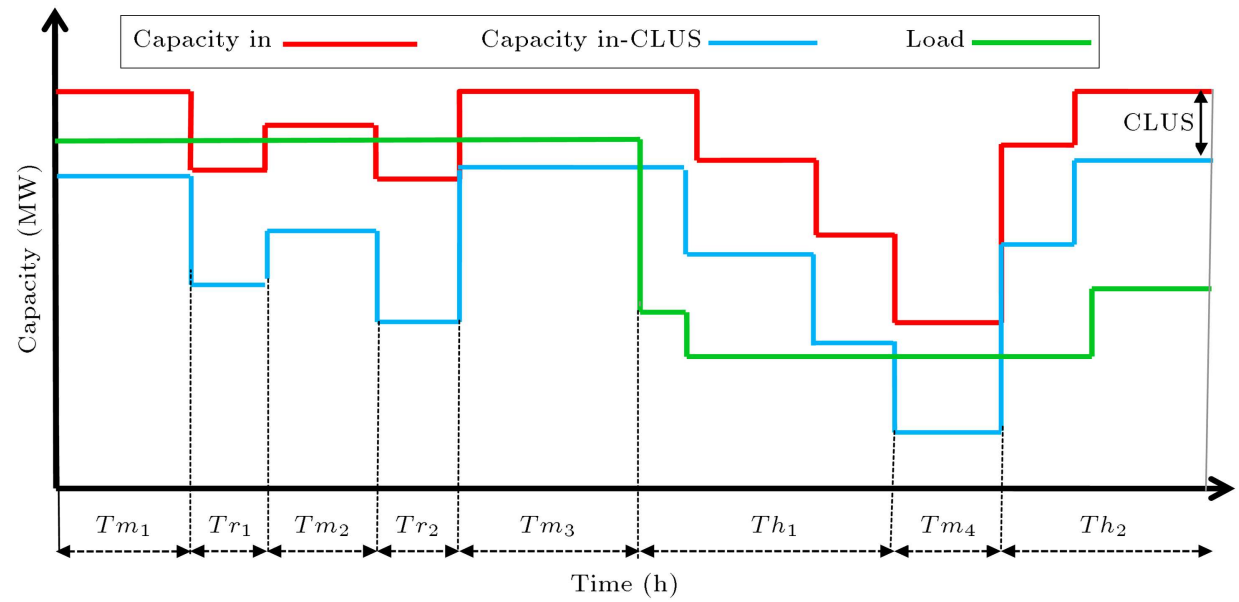

Figure 2. Combined generation and load. 


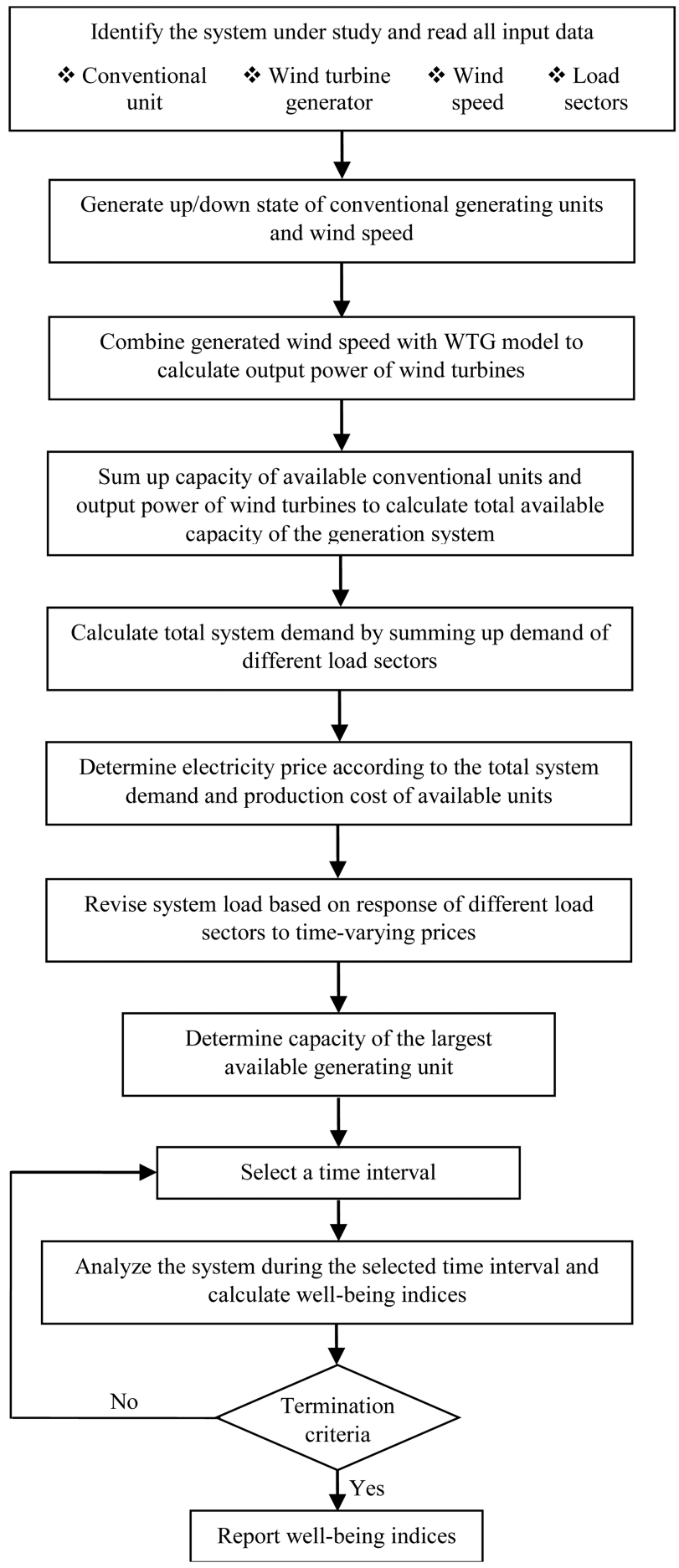

Figure 3. Block diagram of the developed methodology.

The output of this step is the hourly electricity prices;

Step 7: In this step, the hourly electricity prices calculated in Step 6 are provided for customers whose hourly energy use is calculated in Step 5. Load responsiveness is obtained based on the self-elasticity and cross-elasticity coefficients and the hourly variable price [16]. This is done as follows [16]:

$$
\begin{aligned}
L^{k, t}= & \left\{L_{0}^{k, t}+\sum_{t^{\prime}} e^{k}\left(t, t^{\prime}\right) \times \frac{L_{0}^{k, t}}{\rho_{0}^{k, t^{\prime}}} \times\left[\rho^{k, t^{\prime}}-\rho_{0}^{k, t^{\prime}}\right]\right\} \\
& \times\left\{1+\times \frac{e^{k}(t, t)}{\rho_{0}^{k, t}} \times\left[\rho^{k, t}-\rho_{0}^{k, t}\right]\right\}
\end{aligned}
$$

Note that the coefficients in the above expression are assumed to be given. This is because the determination of these coefficients needs thorough social, cultural, and financial investigation, which is beyond the scope of this paper. At the end of this step, revised load profiles associated with diverse load sectors and total system load profile after applying demand response are achieved;

Step 8: To evaluate system well-being criteria, the largest available unit per hour is determined during the simulation time interval;

Step 9: In this step, the evaluation of system well-being criteria for the system with the existence of wind energy is done based on the results of the previous steps as follows:

Step 9-1: The hourly loads are compared to load response times based on the elasticity coefficients and the hourly price, as well as the available capacity of the traditional generators and wind energy accumulated per hour during the simulation time interval. If the load exceeds the total available capacity at that hour, it will be in the risk mode; otherwise, it will be compared to the fraction of the largest available unit by load. If the available capacity minus the largest unit is greater than the load, it is in a state of health; otherwise, it is in a marginal state;

Step 9-2: The procedure is followed in sequence in each state for all of the time periods of simulation;

Step 9-3: Termination criteria are examined in this step. Given the time-consuming nature of the calculations and a large number of time periods of simulations, the calculation termination criterion is checked. If the calculation termination touchstone is met, the calculated indices are reported; otherwise, the process continues;

Step 9-4: In this step, the next time period is selected for examination, and the process returns to Step 9-2.

Well-being calculations by the method mentioned above, i.e., with a particular criterion in the specification of the well-being states such as the largest generating unit, suffer from a fundamental defect. In such conditions, load changes, even small ones, may make great changes in the well-being state probabilities. This 
issue is particularly evident when the largest unit is considerably larger than the others. To solve the issue, it can be cleared up using fuzzy theory. As compared to the conventional method for well-being calculations, where the probability of each state is assigned to one of the well-being states, state probability is appropriately applied to the well-being states in the fuzzy method. In this approach, state probability is modified by a correction coefficient and, thus, is added to the probability of the well-being states. It is of great importance to select the right correction coefficients. There are two parameters involved in calculating the correction coefficients [14]. One of the parameters is the number of usable units whose failure does not lead to load loss in all other units. The second parameter is defined as the scale of the lost load in an event owing to the available capacity loss of the largest unit. In fact, the second parameter demonstrates the effect of the largest unit available in each event on load provision. The probability of healthy state increases as this parameter decreases. Interested readers are referred to [14] for more detailed explanations over the fuzzy approach to calculating the well-being index.

\section{Numerical results}

To demonstrate the effectiveness of the proposed methodology, it is applied to the modified IEEE-RTS; in addition, the impacts of activating demand response on well-being indices are studied in different scenarios. The original IEEE-RTS system has 32 generating units with a total installed capacity of $3405 \mathrm{MW}$ and a peak load of $2850 \mathrm{MW}$ [18]. In the simulations, the load composition data associated with residential, agricultural, official, industrial, governmental, and commercial load sectors given in [19] are used. Table 1 provides the peak demand and load factor associated with seven load sectors. As mentioned earlier, demand flexibility in response to time-varying prices is captured via elasticity coefficients. Table 2 gives the elasticity coefficients associated with different load sectors $[8,9]$. It is worth mentioning that the peak period ranges from

Table 1. Different load sectors peak load (IEEE-RTS).

\begin{tabular}{lcc}
\hline \multicolumn{1}{c}{ Sector } & $\begin{array}{c}\text { Peak load } \\
\text { (MW) }\end{array}$ & $\begin{array}{c}\text { Load factor } \\
(\mathbf{\%})\end{array}$ \\
\hline Industrial & 399.01 & 83.42 \\
Commercial & 284.99 & 54.41 \\
Official & 57.02 & 61.73 \\
Agricultural & 113.1 & 38.38 \\
Large user & 855.01 & 63.44 \\
Residential & 968.99 & 57.48 \\
Government & 145.35 & 56.26 \\
System & 2754.75 & 63.8 \\
\hline
\end{tabular}

17 to 23 , shoulder period from 9 to 17 and 23 to 3 , and off-peak period from 3 to 9 . To calculate timevarying prices that reflect the wholesale market prices, the priority order of the generation units is required. Table 3 gives the priority order used in the simulations.

The stochastic nature of wind speed is modeled by the time-series ARMA model. In this paper, the ARMA model, borrowed from [20], is taken into use as follows:

$$
\begin{aligned}
y_{t}= & 1.772 \times y_{t-1}+0.1001 \times y_{t-1}-0.3572 \times y_{t-3} \\
& +0.0379 \times y_{t-4}+\alpha_{t}-0.5030 \times \alpha_{t-1}-0.2924 \\
& \times \alpha_{t-2}+0.1317 \times \alpha_{t-3} \alpha_{t} \in N I D\left(0,0.524760^{2}\right) .
\end{aligned}
$$

It should be mentioned that mean $(\mu)$ and standard deviation $(\sigma)$ of wind speed are $19.46 \mathrm{~km} / \mathrm{h}$ and $9.7 \mathrm{~km} / \mathrm{h}$, respectively. The WTG units used in this paper are assumed to have a rated power of $2 \mathrm{MW}$ and cut-in, rated, and cut-out wind speeds of $14.4,36$, and $80 \mathrm{~km} / \mathrm{h}$, respectively.

\subsection{Study results}

Here, a few scenarios are examined to study the impacts of demand response and wind penetration on the system well-being.

Scenario 1: In this scenario, the method suggested in the previous section is applied to the IEEE-RTS, and relevant well-being indices are calculated. This scenario serves as a comparison benchmark for the next three scenarios. The served and unserved energy values in each state are also calculated, whose results are shown in Table 4. It is also worth mentioning that the annual unserved energy of the system is $4949 \mathrm{MWh}$;

Scenario 2: This scenario investigates impacts of realizing demand response from different load sectors on the system well-being indices. It is worth mentioning that hourly prices are determined based on the available units and their loading priorities, as depicted in Table 3 . In this scenario, wind power penetration is considered zero. This scenario is simulated, and the achieved well-being indices are presented in Table 5. As can be seen from the table, the well-being indices experience significant improvements when the demand response related to residential and commercial sectors is activated, whereas the indices face negative impacts when activating demand response from large user and agricultural sectors. It is worth mentioning that the best and worst conditions occur when the demand response from the residential and large user sectors is enabled, respectively. These results are in contrast with a common thought that enabling demand response 
Table 2. Elasticity coefficients of different load sectors (IEEE-RTS).

\begin{tabular}{|c|c|c|c|c|c|c|}
\hline & Peak & Mid-peak & Off-peak & Peak & Mid-peak & Off-peak \\
\hline & \multicolumn{3}{|c|}{ Residential } & \multicolumn{3}{|c|}{ Large user, industrial } \\
\hline Peak & -0.26 & 0.065 & 0.048 & -0.13 & 0.054 & 0.039 \\
\hline Mid-peak & 0.065 & -0.26 & 0.04 & 0.054 & -0.13 & 0.032 \\
\hline \multirow[t]{2}{*}{ Off-peak } & 0.048 & 0.04 & -0.26 & 0.039 & 0.032 & -0.13 \\
\hline & \multicolumn{3}{|c|}{$\begin{array}{c}\text { Commercial, official, } \\
\text { governmental }\end{array}$} & \multicolumn{3}{|c|}{ Agricultural } \\
\hline Peak & -0.21 & 0.020 & 0.015 & -0.15 & 0.048 & 0.036 \\
\hline Mid-peak & 0.020 & -0.21 & 0.012 & 0.048 & -0.15 & 0.03 \\
\hline Off-peak & 0.015 & 0.012 & -0.21 & 0.036 & 0.03 & -0.15 \\
\hline
\end{tabular}

Table 3. Priority order of conventional generating units.

\begin{tabular}{ccccccc}
\hline $\begin{array}{c}\text { Generating } \\
\text { unit no. }\end{array}$ & $\begin{array}{c}\boldsymbol{P}_{\max } \\
(\mathbf{M W})\end{array}$ & $\begin{array}{c}\boldsymbol{P}_{\min } \\
(\mathbf{M W})\end{array}$ & $\begin{array}{c}\boldsymbol{\lambda} \\
(\mathbf{f} / \mathbf{y r} .)\end{array}$ & $\mathbf{A}$ & $\mathbf{B}$ & $\mathbf{C}$ \\
\hline $1-6$ & 50 & 0 & 4.42 & 0 & 0.5 & 0 \\
$7-8$ & 400 & 200 & 7.96 & 216.576 & 5.345 & 0.00028 \\
9 & 350 & 150 & 7.62 & 388.25 & 8.919 & 0.00392 \\
$10-13$ & 155 & 60 & 9.13 & 206.703 & 9.2706 & 0.00667 \\
$14-17$ & 76 & 25 & 4.47 & 100.439 & 12.145 & 0.01131 \\
$18-20$ & 197 & 80 & 9.22 & 301.233 & 20.023 & 0.00300 \\
$21-23$ & 100 & 40 & 7.3 & 286.241 & 17.924 & 0.00220 \\
$24-28$ & 12 & 5 & 2.98 & 30.396 & 23.278 & 0.13733 \\
$29-32$ & 20 & 6 & 19.47 & 40 & 37.554 & 0.18256 \\
\hline
\end{tabular}

Table 4. System well-being indices and relevant served energies in Scenario 1.

\begin{tabular}{lccc}
\hline & Healthy & Marginal & Risk \\
\hline Probability & 0.979286 & 0.016302 & 0.004412 \\
Served energy & $14919766.02 \mathrm{MWh}$ & $357543.45 \mathrm{MWh}$ & $97870.29 \mathrm{MWh}$ \\
\hline
\end{tabular}

would always improve system characteristics. This strange observation is mainly because the peak period associated with the large user and agricultural sectors and the system peak period do not coincide. The profiles before and after activating demand response from large users associated with two typical days are depicted in Figure 4. As can be seen, the response from the large user sector causes more severe peak demand since a portion of consumption from the midpeak period shifts to that at the peak time. Moreover,

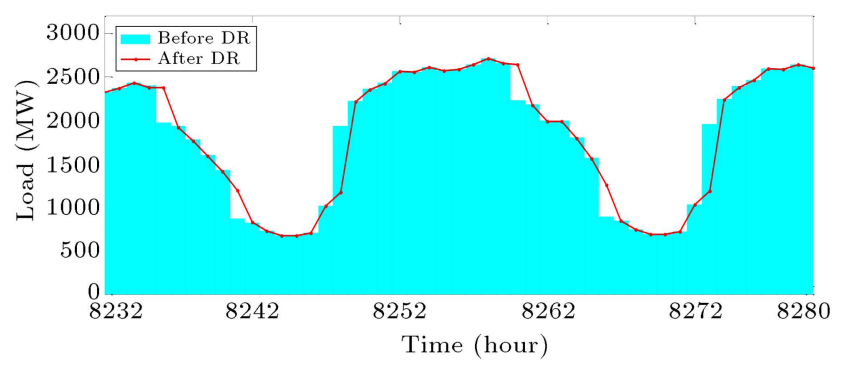

Figure 4. System load profiles with and without demand response for the large user sector. demand response from the other load sectors has little effect due to their negligible flexibility or share from the system demand, or both. Figure 5 also displays system load profiles during two typical days with and without demand response from the residential user sector. As is shown, demand response from the residential sector leads to lower peak demands, thereby enhancing system well-being indices.

Table 5. System well-being indices in Scenario 2.

\begin{tabular}{lccc}
\hline Load sector & Healthy & Marginal & Risk \\
\hline Residential & 0.982500 & 0.0138030 & 0.0036970 \\
Large user & 0.976831 & 0.0179080 & 0.0052100 \\
Industrial & 0.979457 & 0.0160980 & 0.0044450 \\
Commercial & 0.980032 & 0.0156540 & 0.0043143 \\
Governmental & 0.979223 & 0.0163430 & 0.0045340 \\
Official & 0.979383 & 0.0161643 & 0.0044527 \\
Agricultural & 0.979035 & 0.0164010 & 0.0045640 \\
\hline
\end{tabular}


Table 6. System well-being indices and relevant served energies in Scenario 3.

\begin{tabular}{lccc}
\hline & Healthy & Marginal & Risk \\
\hline Probability & 0.983733 & 0.012905 & 0.003362 \\
Served energy & $15017245 \mathrm{MWh}$ & $283308 \mathrm{MWh}$ & $74628 \mathrm{MWh}$ \\
\hline
\end{tabular}

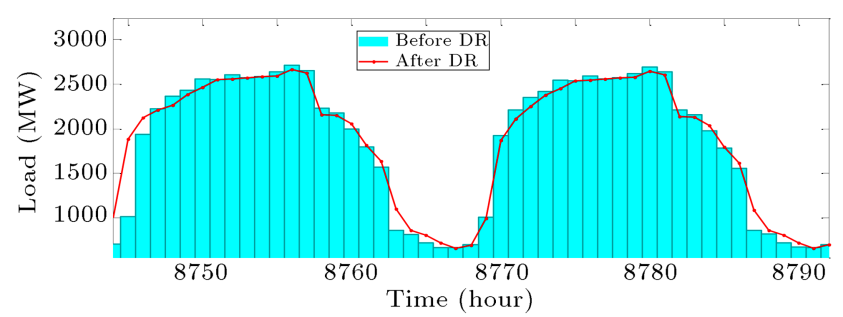

Figure 5. System load profiles with and without demand response for the residential user sector.

Scenario 3: In this scenario, the impacts of wind power penetration on system well-being indices are examined. To do so, 150 WTGs with a total capacity of $300 \mathrm{MW}$ are assumed to be added to the system. Needless to say that demand response is not activated in this scenario. This scenario is simulated, and the obtained results are provided in Table 6 . As can be observed, system well-being has improved to a greater degree than that in the first scenario, where no wind power is integrated in the system. This is because additional WTGs, despite their stochastic out-put, increase the total installed capacity of the system and its available reserve. The value of served energy in the healthy state has increased by $97479 \mathrm{MWh}$, while it has decreased by $23242 \mathrm{MWh}$ in the risk state. In addition, the annual unserved energy of the system experiences an improvement of about $25 \%$ by reaching from 4949 MWh to a value of 3714 MWh;

Scenario 4: In this scenario, the simultaneous effect of enabling demand response and integrating wind power in the system is examined. Here, it is assumed that 150 WTGs with a total installed capacity of $300 \mathrm{MW}$ are added to the system. The scenario is simulated, and the achieved well-being indices are provided in Table 7 . As can be observed, residential customers represent the most affecting load sector in improving the system well-being indices. Based on the enabled demand response from the residential load sector, the probability of being in the risk state has decreased by $37 \%$, as compared to the first scenario. In addition, the index has improved by $17.7 \%$ as compared to the third scenario, where wind power is integrated, yet demand response is not enabled. The probability of being in the marginal state also experiences about $32 \%$ and $14.7 \%$ rates of enhancement as compared to the first and third scenarios, respectively. Finally, the healthy state probability
Table 7. System well-being indices in Scenario 4.

\begin{tabular}{lccc}
\hline Load sector & Healthy & Marginal & Risk \\
\hline Residential & 0.986227 & 0.011007 & 0.002766 \\
Large user & 0.981934 & 0.014254 & 0.003812 \\
Industrial & 0.983788 & 0.012846 & 0.003366 \\
Commercial & 0.984287 & 0.012480 & 0.003233 \\
Governmental & 0.983515 & 0.013039 & 0.003446 \\
Official & 0.983727 & 0.012899 & 0.003374 \\
Agricultural & 0.983426 & 0.013086 & 0.003488 \\
\hline
\end{tabular}

has reached from 0.979286 in the first scenario and 0.983733 in the third scenario to 0.986227 , which can be translated to considerable improvements. Unlike the residential sector, activating demand response from large users is accompanied by negative impacts on the well-being indices. This is mainly because their peak time does not coincide with the system peak period. In case the demand response from large users is enabled, the probability of being at risk increases by $11.3 \%$ as compared to the third scenario, where demand response is not activated. Finally, enabling demand response from the other load sectors leads to less significant changes in the indices since their share of total system demand is low and/or their elasticity coefficients are small. Table 8 gives the served energy of the system during healthy, marginal, and risk states. According to the results, the energy served during the risk state experiences its best and worst conditions when the demand response from residential and large user sectors is enabled, respectively. Further, the maximum and minimum values of energy served during the system healthy state are provided when residential and large user sectors' response is activated, respectively. Finally, it is worth mentioning that the most significant decrease in the value

Table 8. Served energy (MWh) in system well-being states in Scenario 4.

\begin{tabular}{lccc}
\hline Load sector & Healthy & Marginal & Risk \\
\hline Residential & 15037722 & 239497 & 60858 \\
Large user & 14943713 & 313714 & 84821 \\
Industrial & 14995563 & 281899 & 74714 \\
Commercial & 15025928 & 273296 & 71540 \\
Governmental & 15010925 & 286592 & 76649 \\
Official & 15016835 & 283112 & 74913 \\
Agricultural & 15007408 & 288065 & 77701 \\
\hline
\end{tabular}


of unserved energy is observed when the residential sector response is enabled. In case demand response from residential load is realized, the system unserved energy decreases by $38 \%, 26 \%$, and $18 \%$ as compared to the first, second, and third scenarios, respectively.

\subsection{Sensitivity analysis}

In order to examine the impacts of wind power penetration on the performance of the demand response program, a few studies with 50, 100, 200, 300, 400, and $500 \mathrm{MW}$ wind power installations are simulated. The achieved results including well-being indices and served energies during each system state are given in Tables 9 and 10 for wind power penetrations of 50 and $500 \mathrm{MW}$. In addition, Figure 6 displays the changes in risk state probability versus wind power penetration and different load sectors responses. As can be seen, system well-being is more enhanced as more wind power is installed. Moreover, the impacts of response from the load sectors decrease by increasing the penetration of wind energy in the system. For instance, if $50 \mathrm{MW}$ wind power is installed, the system risk probability decreases by $1.7 \%$ as compared to that of the original system. Moreover, the risk probability experiences a greater enhancement by $16.77 \%$ if the response from the residential sector is realized. However, the index has improved by $34 \%$ if $500 \mathrm{MW}$ wind power is integrated in the system and by $45.9 \%$ if the response from the residential sector is applied, too.

As compared to the first scenario with an annual

Table 9. Well-being indices of the system with 50 and $500 \mathrm{MW}$ wind capacities.

\begin{tabular}{|c|c|c|c|c|}
\hline $\begin{array}{l}\text { Wind } \\
\text { power }\end{array}$ & Load sector & Healthy & Marginal & Risk \\
\hline \multirow{7}{*}{ 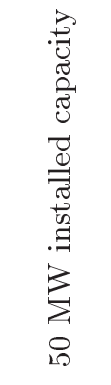 } & Residential & 0.983044 & 0.013359 & 0.003597 \\
\hline & Large user & 0.977833 & 0.017189 & 0.004978 \\
\hline & Industrial & 0.980088 & 0.015566 & 0.004346 \\
\hline & Commercial & 0.980671 & 0.015126 & 0.004203 \\
\hline & Governmental & 0.979761 & 0.015790 & 0.004449 \\
\hline & Official & 0.980016 & 0.015629 & 0.004355 \\
\hline & Agricultural & 0.979672 & 0.015585 & 0.004470 \\
\hline \multirow{7}{*}{ 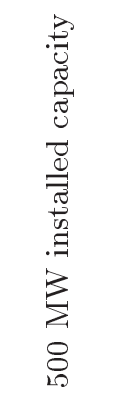 } & Residential & 0.987975 & 0.009638 & 0.002387 \\
\hline & Large user & 0.984203 & 0.012522 & 0.003275 \\
\hline & Industrial & 0.985828 & 0.011279 & 0.002893 \\
\hline & Commercial & 0.986262 & 0.010957 & 0.002781 \\
\hline & Governmental & 0.985589 & 0.011451 & 0.002960 \\
\hline & Official & 0.985774 & 0.011326 & 0.002900 \\
\hline & Agricultural & 0.985510 & 0.011498 & 0.002992 \\
\hline
\end{tabular}

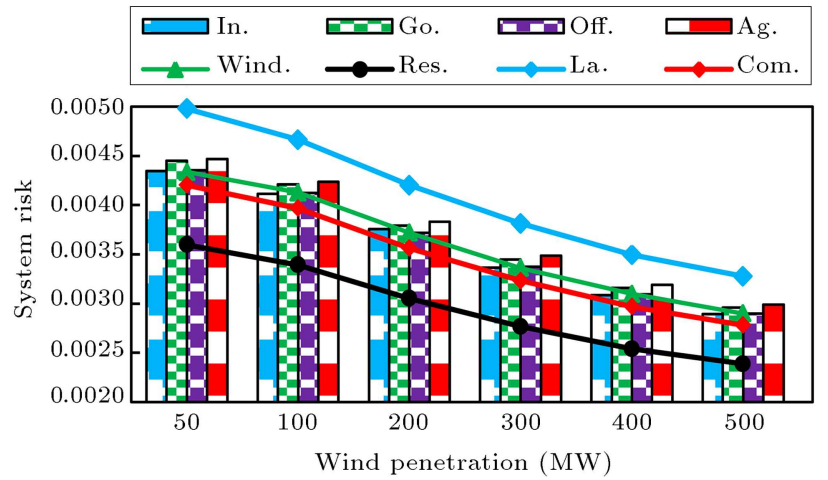

Figure 6. System risk probability versus wind penetration and load sectors response.

unserved energy amount of 4949 MWh, the residential sector has the most effective response such that a $19.8 \%$ decrease occurs in case of installing a wind capacity of $50 \mathrm{MW}$ along with a $47.6 \%$ decrease in case of installing a $500 \mathrm{MW}$ wind capacity. In addition, the large user sector has the least effective response with an $11.5 \%$ increase in the unserved energy when $50 \mathrm{MW}$ wind is integrated and a $27 \%$ decrease when $500 \mathrm{MW}$ wind capacity is installed.

As compared to the second scenario where the unserved energy has reduced by $35.4 \%$, when $500 \mathrm{MW}$ wind is added, the response from the large user sector results in an $8.4 \%$ increment. Figure 7 displays unserved energy changes in the presence of different load sector responses. As can be observed, residential

Table 10. Served energy (MWh) in states of the system with 50 and $500 \mathrm{MW}$ wind capacities.

\begin{tabular}{|c|c|c|c|c|}
\hline $\begin{array}{l}\text { Wind } \\
\text { power }\end{array}$ & Load sector & Healthy & Marginal & Risk \\
\hline \multirow{7}{*}{ 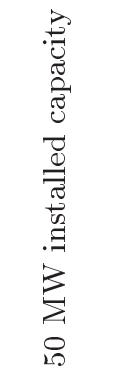 } & Residential & 14969712 & 290273 & 79085 \\
\hline & Large user & 14854537 & 378997 & 109575 \\
\hline & Industrial & 14915250 & 382505 & 96381 \\
\hline & Commercial & 14946911 & 370719 & 92946 \\
\hline & Governmental & 14928738 & 389046 & 98789 \\
\hline & Official & 14935642 & 384075 & 96593 \\
\hline & Agricultural & 14925132 & 348619 & 99473 \\
\hline \multirow{7}{*}{ 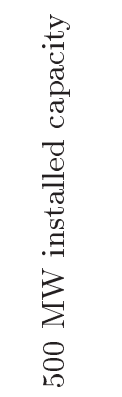 } & Residential & 15074468 & 209854 & 52512 \\
\hline & Large user & 14992590 & 275719 & 72869 \\
\hline & Industrial & 15039540 & 247663 & 64214 \\
\hline & Commercial & 15069017 & 240078 & 61530 \\
\hline & Governmental & 15056490 & 251818 & 65836 \\
\hline & Official & 15061728 & 248738 & 64387 \\
\hline & Agricultural & 15053189 & 253258 & 66667 \\
\hline
\end{tabular}




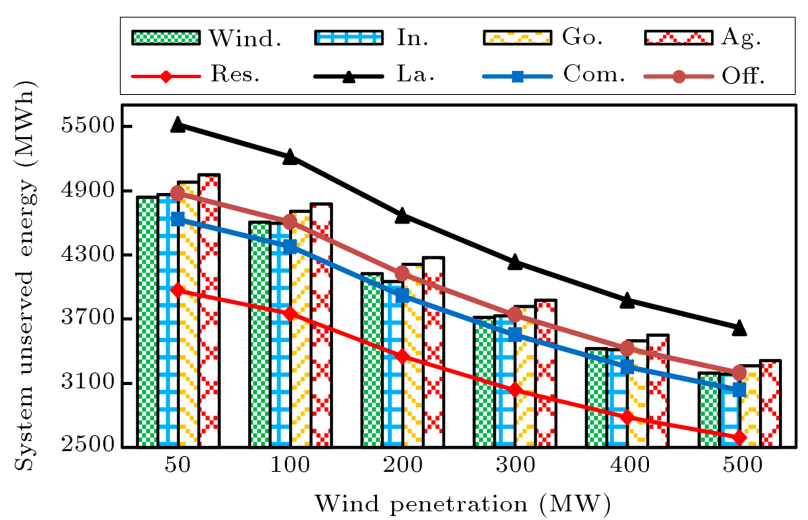

Figure 7. System unserved energy versus wind penetration and load sectors response.

and commercial loads are the most effective concerning the system unserved energy; industrial and official loads are almost ineffective; large-user, agricultural, and public loads have the worst effects on the system unserved energy. Actually, according to the results, the demand response from large users, agricultural, and public loads increases the system unserved energy. As also stated earlier, the main reason behind this strange observation is related to the negative correlation between these load sectors and the total system load. As another observation, it can be seen from the figure that the gradient values of the curves decrease as more wind power is integrated into the system. This can be translated into lower performances of demand response as more wind power is injected into the system.

As shown in Figure 8, a reduction in system unserved energy caused by realizing demand response from residential and commercial load sectors is observed when the wind penetration level increases. By applying the demand response from residential customers, the system unserved energy decreases by 875.32 MWh when wind power penetration is $50 \mathrm{MW}$, while the reduction reaches $603 \mathrm{MWh}$ when $500 \mathrm{MW}$ wind power is penetrated. In case of applying demand response form the commercial load sector, the unserved energy reduces from 209.38 MWh to $159 \mathrm{MWh}$ when wind power penetration increases from $50 \mathrm{MW}$ to

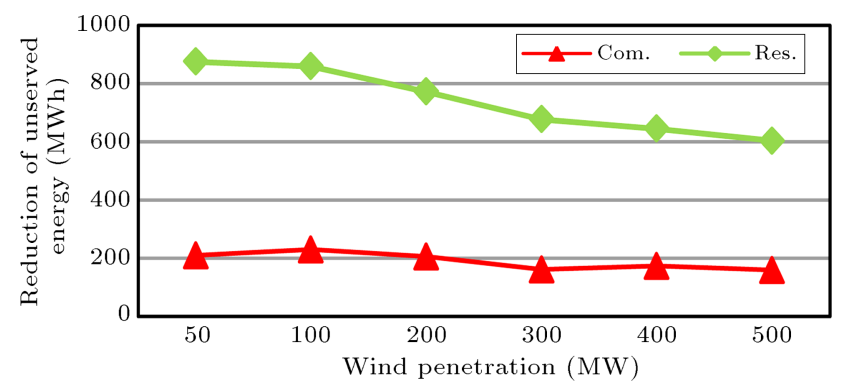

Figure 8. Loss of energy reduction with the increase of wind penetration.

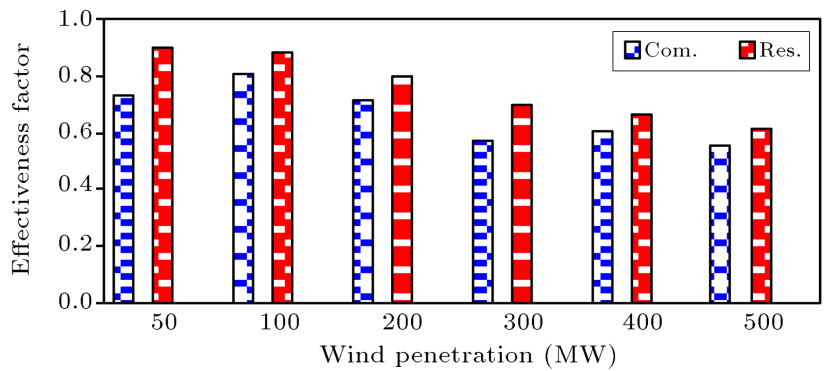

Figure 9. Effectiveness factor in commercial and residential loads versus wind penetration.

$500 \mathrm{MW}$. These findings are seen because the system reliability and unserved energy are enhanced as the wind power penetration increases since it provides some additional generation capacity. As another observation, with any penetration of wind power, demand response from the residential load sector is much more effective than that from the commercial load sector. This is because the residential load sector has a larger share of system demand with larger elasticity coefficients. As stated earlier, the residential and commercial sectors are the most effective load sectors on well-being indices. To investigate the effectiveness of enabling demand response from the same amount of load, one can normalize the unserved energy reduction via dividing it by the peak demand of the load sector whose response is activated. The normalized effectiveness (called effectiveness factor) associated with residential and commercial load sectors at different penetration levels of wind power is calculated, as displayed in Figure 9. As can be observed, enabling demand response from residential loads is relatively more effective. This can be due to the larger elasticity coefficients of the residential load sector than those of the commercial load sector.

\section{Conclusions}

This paper studied the impacts of enabling demand response on well-being indices of systems with different wind power penetration levels. The demand behavior in response to dynamic prices was captured via self and cross elasticity coefficients. In the studies, seven different load sectors including residential, commercial, industrial, large user, agricultural, governmental, and official consumers were examined. As detected in the simulation outcomes, enabling demand response from different load sectors has different effects on system well-being. This is largely owing to different shares from system load, different elasticity coefficients, and different load profiles. It was demonstrated that the demand response from residential and commercial load sectors had significant positive impacts on system wellbeing. It was also shown that activating demand response did not necessarily improve the system well- 
being since demand response from large users degraded system well-being. This resulted from both the flexibility and load profile of that load sector. In dynamic pricing, prices in peak load period were higher than those during medium load and low load, and the values of shift and reduction of load were determined based on load elasticity. Since residential and commercial loads were used within the early hours of the night, their responses were exaggerated when electricity was more expensive, while industrial loads were less effective as they were less flexible and often unavailable during the day. It was also revealed that the potential positive impacts of demand response decreased as more wind power was hosted by the system. This is because installing wind power provides the system with additional generation capacity, which in turn enhances system well-being. Moreover, it makes sense that enabling demand response of the system whose well-being has already improved is less effective.

\section{Nomenclature}

$y_{t} \quad$ The time series value at time

$\Phi_{i} \quad$ Auto-regressive average coefficient, $i=1,2, \cdots, n$

$\Theta_{j} \quad$ Moving average coefficient, $j=$ $1,2, \cdots, m$

$\alpha_{t} \quad$ A normal white noise process with zero mean and variance of $\sigma_{\alpha}^{2}$

$P_{r} \quad$ Rated power output

$V_{c i} \quad$ The cut-in wind speed

$V_{r} \quad$ The rated wind speed

$V_{c o} \quad$ The cut-out wind speed of the WTG

$\mathrm{WK}_{t} \quad$ The simulated wind speed at time $t$

$L_{0}^{k, t} \quad$ Energy use of load sector $k$ during time interval $t$ before response to time-varying prices

$L^{k, t} \quad$ Energy use of load sector $k$ during time interval $t$ after providing response to time-varying prices

$\rho_{0}^{k, t}, \rho^{k, t} \quad$ Electricity prices offered to load sector $k$ at time interval $t$

$e^{k}\left(t, t^{\prime}\right) \quad$ Elasticity of energy use of load sector $k$ at time interval $t$

$\mu \quad$ Mean deviation of wind speed

$\sigma \quad$ Standard deviation of wind speed

$L_{0}^{k, t} \quad$ Energy use of load sector $k$ during time interval $t$ before response to time-varying prices

$L^{k, t} \quad$ Energy use of load sector $k$ during time interval $t$ after response to time-varying prices

\section{References}

1. Cecati, C., Cito, C., and Siano, P. "Combined operations of renewable energy systems and responsive demand in a smart grid", IEEE Trans. Sust. Energy, 2(4), pp. 468-476 (2011).

2. Etherden, N. and Bollen, M.H.J. "Dimensioning of energy storage for increased integration of wind power", IEEE Trans. Sust. Energy, 4(3), pp. 546-553 (2013).

3. Safdarian, A., Fotuhi-Firuzabad, M., and Aminifar, F. "Compromising wind and solar energies from the power system adequacy viewpoint", IEEE Trans. Power Syst., 27(4), pp. 2368-2376 (2012).

4. Madaeni, S.H. and Sioshansi, R. "Measuring the benefits of delayed price-responsive demand in reducing wind-uncertainty costs", IEEE Trans. Power Syst., 28(4), pp. 4118-4126 (2013).

5. Sioshansiand, R. and Short, W. "Evaluating the impacts of real-time pricing on the usage of wind generation", IEEE Trans. Power Syst., 24(2), pp. 516524 (2009).

6. Finn, P., Fitzpatrick, C., and Leahy, M. "Increasing penetration of wind generated electricity using real time pricing and demand side management", IEEE Int. Symp. Sust. Syst. and Tech., pp. 1-6 (2009).

7. Bilinton, R., Huang, D., and Wangdee, W. "Effect of demand side management on bulk system adequacy evaluation", IEEE Conf. PMAPS (2010).

8. Kirschen, D.S., Strbac, G., and Cumperayot, P. "Factoring the elasticity of demand in electricity prices", IEEE Trans. Power Syst., 15(2), pp. 612-617 (2000).

9. Thimmapuram, P. and Kim, J. "Consumers Prices elasticity of demand modeling with eco-nomic effects on electricity markets using an agent-based model", IEEE Trans. Smart Grid, 4(1), pp. 390-397 (2013).

10. Hassanzadeh, M.N., Fotuhi-Firuzabad, M. and Safdarian, A. "Wind energy penetration with load shifting from the system well-being viewpoint", International Journal of Renewable Research (IJRER), 7(2), pp. 111 (2017).

11. Billinton, R., Karki, R., Gao, Y., Huang, D., Ho, P., and Wangdee, W. "Adequacy assessment considerations in wind integrated power systems", IEEE Trans. Power Syst., 27(4), pp. 2297-2305 (2012).

12. Giorsetto, P. and Utsurogi, K.F. "Development of a new procedure for reliability modeling of wind turbine generators", IEEE Trans. Power App. Syst., 102(1), pp. 134-143 (1983).

13. Billinton, R. and Karki, B. "Well-being analysis of wind integrated power systems", IEEE Trans. Power Syst., 26(4), pp. 2101-2108 (2011).

14. Fotuhi-Firozabad, M. and Abiri-Jahromi, M.A. "A fuzzy logic based approach to determine sys-tem wellbeing indices", Euro. Trans. Electric. Power, 18, pp. 636-654 (2008). 
15. Billinton, R. and Fotuhi-Firozabad, M. "A basic framework for generating system operating healthy analysis", IEEE Trans. Power Syst., 9, pp. 1610-1617 (1994).

16. Alami, H., Yousefi, G.R., and parsaMoghadam, M. "Demand-response modeling considering interruptible/curtailable loads and capacity market programs". App. Energy, 87, pp. 243-250 (2010).

17. Hassanzadeh, M.N., Fotuhi-Firuzabad, M., and Safdarian, A. "Impacts of demand response from different sectors on generation system well being", J. Electr. Eng. Technol., 12(5), pp. 1921-718 (2017).

18. IEEE-PS APM Subcommittee "IEEE reliability test system", IEEE Trans. Power App. Syst., PAS-98(6), pp. 2047-2054 (1979).

19. Sankarakrishnan, A. and Billinton, R. "Sequential Monte Carlo simulation for composite power system reliability analysis with time varying loads", IEEE Trans. Power Syst., 10(3), pp. 1540-1545 (1995).

20. Wangdee, W. and Billinton, R. "Considering loadcarrying capability and wind speed correlation of WECS in generation adequacy assessment", IEEE Trans. Energy Conv., 21(3), pp. 734-741 (2006).

\section{Biographies}

Muhammad Naseh Hassanzadeh received BSc in Electrical Engineering from Electrical and Computer Engineering faculty of Tabriz University, Iran in 1996. He received MSc in Electrical Engineering from Electrical Engineering Faculty of Sharif University, Tehran, Iran in 1999 and is presently pursuing the $\mathrm{PhD}$ degree at Islamic Azad University, Science and Research Branch.
Mahmud Fotuhi-Firuzabad (F'14) received the BS degree from the Sharif University of Technology, Tehran, Iran in 1986, the MS degree from Tehran University, Tehran in 1989, and the MS and $\mathrm{PhD}$ degrees from the University of Saskatchewan, Saskatoon, SK, Canada in 1993 and 1997, respectively, all in Electrical Engineering. Currently, he is a Professor at the Department of Electrical Engineering, and the President of Sharif University of Technology. He is a member of the Center of Excellence in Power System Management and Control. Dr. Fotuhi-Firuzabad serves as an Editor of the IEEE Transactions on Smart Grid.

Amir Safdarian (S'11-M'15) received the BSc degree from Tehran University, Tehran, Iran in 2008 and obtained MSc and PhD degrees from Sharif University of Technology, Tehran in 2010 and 2014, respectively, where he is currently an Assistant Professor. He was a recipient of the 2013 IEEE Power System Operation Transactions Prize Paper Award and 2016 IEEE Iran Section Best PhD Dissertation Award. His research interests include power system reliability and resilience, distribution network operation and planning, and smart grid issues.

Soodabeh Soleymani received the BS, MS, and PhD degrees from the Sharif University of Technology, Tehran, Iran, 1997-2007, all in Electrical Engineering. Currently, she is a faculty member and an Associate Professor of Science and Research Branch, Islamic Azad University. Her current research interests are power system studies including electric machines, generation and transmission expansion planning, and electricity market. 